\title{
Abstracts
}

\section{Martin Koch}

\section{World Organizations}

(Re-)Conceptualizing International Organizations

ZIB, Vol. 21, No. 1, pp. 5-38

This contribution aims to theoretically re-conceptualize international organizations as world organizations. As International Relations theories primarily concentrate on the linkage between states and international organizations they mostly neglect conceptualizing the latter and their changing roles in world politics. This contribution therefore suggests conceptualizing international organizations from an organization studies perspective as open systems embedded in and influenced by its societal environment, i.e. world society. Thus, international organizations, having no spatial restrictions concerning its membership, shall be conceived as world organizations by differentiating four key characteristics: world semantic, inner world, external relations, and world order. Taking an open system perspective as the common ground, these four characteristics of world organizations will be illustrated by focusing on the World Trade Organization and World Bank.

Keywords: international organizations, organization studies, world society, world trade organization, world bank.

\section{Andrea Schneiker}

\section{Epistemic Communities and Transnational Governance}

Humanitarian Security Experts as Engines of Change

ZIB, Vol. 21, No. 1, pp. 39-78

Since a few years, humanitarian non-governmental organisations (NGOs) are faced with increased insecurity in some of the regions in which they work. Given that humanitarians traditionally consider themselves to be protected by their neutrality, assuming that assisting those in need will automatically ensure acceptance of their work by the local population and the conflicting parties, the increased insecurity challenges the identity of humanitarian NGOs. Hence, addressing this insecurity proves challenging for NGOs, which is why they tend to shy away from taking steps in this direction. Nevertheless, many humanitarian NGOs are changing their attitudes towards security issues and have, for example, established an internal security management and exchange security-relevant information among each other. An analysis based on 27 semi-structured interviews reveals that this development can be explained by the activities of an epistemic community of humanitarian secu- 
rity experts. The latter is neither primarily nor exclusively composed of scientists, but of individuals coming from different sectors who share a professional expertise, on the one hand, and a particular set of values, on the other. Those two elements explain not only the internal cohesion of the epistemic community, but also why the standards it formulates are accepted by other non-state and even by governmental actors and, hence, why the epistemic community can be considered to dispose of authority.

Keywords: humanitarian non-governmental organisations, epistemic communities, security, networks, identity.

\section{Nele Noesselt}

The Limits of »Non-Western« International Relations Theory Approaches Reconstructing the Meta-Dimension of Theory Debates in China ZIB, Vol. 21, No. 1, pp. 79-107

Since the early 1980s, Chinese scholars have been engaged in a debate about the formulation of a »Chinese « theory of International Relations (IR). Recently, this debate has caught the attention of the international academic community, mainly of those following a postcolonial approach. They regard IR theory formulation in " non-Western « contexts as a potential contribution to the internationalization of general IR. But can the Chinese debate really be embedded into »Western« theory frames? Does the Chinese debate, as commonly assumed, contain elements of a » non-Western « theory formulation? This study sheds light on the background of IR debates in China (1980-2013). It discusses the meta-dimensions of »Chinese« IR and contrasts them with the views and expectations of (postcolonial) IR research in the »West $\ll$.

Keywords: chinese school of ir, meta-theory, »non-western« ir, post-positivism, post-colonialism.

\section{Ali Arbia}

\section{The Republic of Letters 2.0}

ZIB, Vol. 21, No. 1, pp. 109-127

Public discourse and the exchange amongst specialists is moving increasingly into the virtual space. The so-called Web 2.0 offers new possibilities to the discipline of International Relations for internal as well as external communication, and changes how we engage in the scientific endeavor. Communication is fast, decentralized and addresses new audiences that could previously not be reached. This creates risks and opportunities. Instead of using the new options and sharpening the profile of the discipline in politics and in the public perception, we all too often lose sight 
of the opportunities while staring at the potential risks. There is a danger of a widening language gap in the discipline of International Relations and of a loss of relevance. It could happen that the new edition of the Republic of Letters will take place without the participation of the German speaking world.

Keywords: international relations, blogs, web 2.0, science communication, new media.

\section{Kimo Quaintance}

\section{Teaching IR with New Media}

ZIB, Vol. 21, No. 1, pp. 129-141

New media is a valuable object and medium of study in International Relations (IR). As an object of study, the impact of new media speaks to the questions about the nature of information in the digital age, the behavior of networked individuals, and emerging digital identities that are central to many important current debates in IR. As a medium, it can give our students greater opportunities to collect and share knowledge, collaborate meaningfully with their classmates and the outside world, and manage complex knowledge flows in order to solve problems. This paper addresses the information literacy challenges facing our students in the digital age, along with significant themes where new media can illuminate critical current issues in IR, and offers recommendations for applying new media as a method for enhancing student engagement and learning outcomes.

Keywords: teaching, new media, digital age, collaboration, information literacy.

\section{Hanan Badr/Thomas Demmelhuber}

Authoritarian Regimes, New Media and the "Regime Dilemma«

ZIB, Vol. 20, No. 2, pp. 143-160

There is a consensus in Social Sciences and other disciplines that media plays an important role in times of political change. Yet, in recent years, the s npecific role of Information and Communication Technologies (ICTs) in political transformation processes receives more scholarly attention, especially against the background of its dissemination and further (technical) developments. Hence, this paper focuses on the concrete structural and functional innovations achieved by New Media (i.e. social media and microblogs) and develops the concept of three dilemmas each authoritarian regime encounters in a different way. This paper poses the central question what potential New Media embodies during different phases of political change. It focuses on the Arab Spring with a case study on Egypt. Based on empirical data derived from comprehensive field work, a micro study will categorize the 
role of New Media during the different phases of political upheaval in Egypt since 2011.

Keywords: internet, political transformation, authoritarianism, regime dilemmas, egypt.

\section{Nele Noesselt}

\section{International Dimensions of the »Chinese« Internet}

ZIB, Vol. 20, No. 2, pp. 161-177

The Internet in China is often referred to as a hermetically closed intranet behind the Great Firewall. Most studies focus on the issues of censorship versus cyber dissent. The international dimension of the Internet is often neglected. This reduction of the analysis of the Internet to the national context misconceives the fact that the cyberspace already plays a key role in foreign policy decision-making and international relations. In addition to traditional international relations, coordinated between national governments, a multitude of new processes of interaction has emerged. Via the Internet national interests groups can articulate their views and can directly address the people or governments of other states. Moreover, the digitalization of politics causes the international security situation to change: New fields of conflict in international politics which have become visible in the cyber context (cyberattacks; cyber espionage) require new forms of global constitutionalization and a deepening of existing dialogue mechanisms.

Keywords: china, cyber-strategy, e-government, micro-blogs, public diplomacy. 